$\xi=$

\title{
Evaluation of Kenaf/Polyester Fiber Blended Sliver Produced from Carding Machine
}

\author{
N.W. Mohd Rusli ${ }^{1}$, A.H. Abdul Rashid ${ }^{1 *}$, M.R. Ahmad ${ }^{2}$, M.N. Roslan ${ }^{1}$, D. Mohd Harun ${ }^{1}$, S. Che Ismail ${ }^{1}$

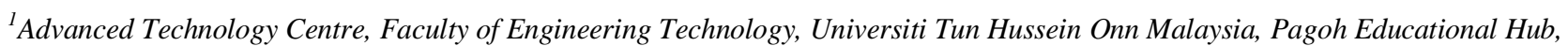 \\ Pagoh, Muar, Johor, Malaysia \\ ${ }^{2}$ Textile Research Group, Faculty of Applied Sciences, Universiti Teknologi MARA, 40450 Shah Alam. Selangor, Malaysia \\ *Corresponding author E-mail: azrin@uthm.edu.my
}

\begin{abstract}
Controlling sliver evenness is very important since this parameter can affect the quality of the yarn produced. In kenaf sliver production, kenaf fibres alone could not form a good sliver. Thus, fibres such as polyester are needed to blend with kenaf to improve fibre cohesiveness and form a better sliver. The aim of this study is to identify the optimum ratio of kenaf that can be used for sliver production. The heart of the process for the production of kenaf/polyester slivers is carding. The weight percentage of kenaf used for the kenaf/polyester sliver production was 50\%, 60\% and $70 \%$. After sliver formation, the waste percentage, diameter and size were determined. The sliver images were analysed under video analyser and captured by digital SLR camera to observe the fibre blending. The research showed that lower percentage of kenaf offered better waste percentage and sliver diameter. Whereas, sliver size showed some decrement with an increment of kenaf fibre percentage. The presence of polyester in the production of kenaf/polyester sliver seems to play an important role to bind the kenaf fibres together.
\end{abstract}

Keywords: Carding; Hybrid Sliver; Kenaf; Polyester; Sliver

\section{Introduction}

Natural fibres have been seen as one of the most promising materials because of their far more renewable and biodegradable properties which fulfil the sustainability initiatives. Due to environmental concerns, natural fibre are increasingly being considered as an environmental friendly material to substitute the usage of synthetic fibres. Based on previous research, results showed that natural fibre composites have high potential for better ductility, toughness and have a significant increase in tensile, flexural and impact strength [1][2]. Due to all the advantages offered, the potential of natural fibre as one of the main materials to produced yarn are clearly undeniable. One of natural fibres that are widely being research nowadays is kenaf [3].

Kenaf is a multipurpose plant with the entire kenaf plant, leaves, tender shoot, woody core, bast fibre and seed are valuable in different usages. The end products of kenaf fibres depend on the portion fibre used [4]. However, kenaf fibres are usually highly productive for their stalk from which the fibre is extracted. Traditionally, the allied fibres are used as cords, ropes and twine [5], and many studies have also shown that it offers good opportunity as reinforcement material for composites. Kenaf fibres also offer advantages as composites, being lightweight and environmentally friendly [6]. Conventionally, kenaf is used as a cordage crop to produce twine, rope, carpet backing, burlap and sackcloth [7]. Kenaf's bast fibre is responsible for applications such as nonwoven fabric and reinforced composite materials for automotive, packaging, and aerospace. Kenaf is also commonly used in woven structures [8]. So far, research reported on the usage of kenaf fibres in the form of yarn is very limited.
One of the downstream processes is to produce kenaf fibres into yarn. This has typically been a challenge since $100 \%$ kenaf fibres are extremely difficult to produce a yarn. This is due to the characteristics of kenaf fibres which are a bit brittle and coarse. Several approaches have been implemented to enhance the performance of the kenaf in the making of staple yarn. The common processes involved in producing staple yarns are carding, roving and spinning [9] [10].

Generally, the carding process also have an influence on sliver evenness. Sliver evenness is an imperative parameter that should be considered as it will affect the performance of the yarn produced. Previous researcher claimed that the auto-levelers mounted on draw frame machine should be adjusted correctly in order to obtain the suitable sliver evenness [11]. Hence, this research aimed to investigate the physical properties of kenaf/polyester hybrid sliver subjected to different blending ratios. In this study, three different weight ratios of kenaf/polyester sliver were prepared, produced at a constant carding speed.

\section{Materials and Methodology}

\subsection{Materials}

The kenaf fibres were supplied by a local kenaf plant provider, Kenaf Bio Solution Sdn. Bhd., Kuala Lumpur, Malaysia. Fibres were extracted manually after retting them in water for a few days and dried under the sun. The fibres were cut according to the specified average length of $40 \mathrm{~mm}$ (Fig 1). The polyester fibres were 1.2 denier in size with an average length of $32 \mathrm{~mm}$. 


\subsection{Sliver Preparation}

The kenaf and polyester fibres were prepared into three different weight ratios: 50:50, 60:40 and 70:30. The polyester fibres were mixed with kenaf fibres as shown in Fig. 1 (a), by weight basis based on percentages mentioned earlier. After mixing, they were manually fed into the opener machine refer Fig. 1 (b). Here, the kenaf fibres were opened into individual fibres and blended with the polyester based on the ratio mentioned earlier. Then, the mixed of kenaf and polyester were fed to the carding machine as in Fig. 1 (c). The parameters of the carding machine were kept constant where the main cylinder speed was $43 \mathrm{rpm}$, outlet speed at $25 \mathrm{rpm}$, inlet speed at $6.8 \mathrm{rpm}$ and the twister running at $17.9 \mathrm{rpm}$. The carding process basically improved fibre evenness and parallelization and convert the fibre blends into sliver form.

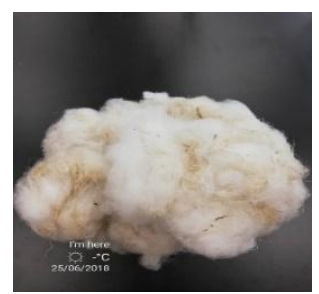

(a)

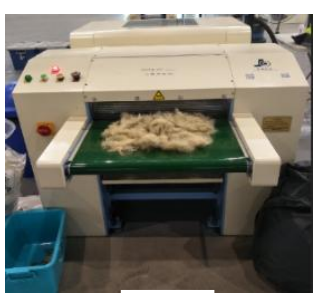

(b)

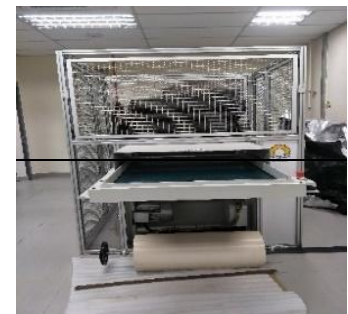

(c)

Fig. 1: (a) Blended kenaf/polyester fibre; (b) Opener machine; and (c) Carding machine

\subsection{Sliver Analysis}

\subsubsection{Physical evaluation}

The diameter and size of the slivers were evaluated. The diameters of the slivers were measured using Nikon MM-200 Tool Maker Microscope. An average of 15 readings for every different weight and ratios were recorded. Whereas the sizes of the slivers were measured in Hank. Hank refers to the length over weight of sliver.

\subsubsection{Waste percentage}

The waste percentage for the sliver were calculated in carding process as in (1). It is necessary to eliminate about as much as fibres as foreign materials at this stage. Waste removed from the carding process is very important as it reflects the cleaning efficiency of the carded sliver. The waste percentage for carded sliver were calculated as below:

\section{Waste percentage $(\mathrm{g} / \mathrm{b})=$}

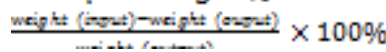

\subsubsection{Microscopic View}

The images of fibre formation of the blended slivers were taken using a digital SLR camera prior under fixed distance $(5 \mathrm{~cm})$ and also imaged using video analyser. The images were taken to observe the position of the kenaf fibres within the sliver structure.

\section{Results and Discussion}

\subsection{Sliver Diameter and Size Result}

The mean grouping was analysed using one way analysis via analysis of variance (ANOVA). The mean values for each kenaf/polyester hybrid sliver are shown in Table 1 for the samples of different blending ratio. Table 1 highlights that the F-value was high, and the P-value was less than 0.05 for the diameter, waste percentage and sliver size (highlighted with bold font). This condition indicates that the blended ratios has significant effects on these key responses.

The ratio of the constituent fibres in the blend is very important for yarn quality and processing point of view. It is more important when fibres with dissimilar characteristics are spun together in a blend to produce a better sliver [12]. Distribution of residuals demonstrates a lower degree of variability with $\mathrm{R}^{2}$ value of $72 \%$. Therefore, data obtained from the experiment can be accepted as stable. Main effects plot of mean diameter data is displayed in Fig. 2 (a). Weight of $70 \mathrm{~g}$ was found to exhibit higher diameter. This is important to note that the sliver also depends on the fibre size distribution and/or aspect ratio of the fibres [13]. Higher diameter occurs with the increment of kenaf ratios. The diameter observed to increase gradually as the kenaf percentages increased. It can be concluded that the diameter will increase because of the presence of kenaf ratio is higher than polyester. The properties of kenaf itself are poor adhesion and cannot interlocked with each other and give the sliver becomes more hairiness. Reported by other researcher, as the ratio of polyester in the blend increases, yarn tenacity, liveliness, and elongation increases whereas yarn hairiness diminished; furthermore, yarn evenness becomes better with increase in polyester content [14]. As kenaf ratios became dominant in this study, it caused the sliver diameter become increased.

Different kenaf/polyester blending ratio showed significant effects towards sliver size with ( $\mathrm{p}$-value $<0.05)$ where $\mathrm{R}^{2}$ value was recorded as $98 \%$, which indicates stable data with a high degree of variability. It is expected due to staple length and the presence of unvarying fineness of polyester fibre, which caused more evenness to the yarn in cross-section [14]. Main effect plot of average data for the size of sliver are displayed in Fig. 2 (b). The result illustrated that $50 \%$ of kenaf give the highest mean of sliver size, whereas the $70 \%$ of kenaf showed the lowest size of kenaf sliver. Nature properties of kenaf is brittle. As it passing through the carding process, it will produce more waste. Thus, with increment of kenaf ratios, it will reduce the size of sliver.

\subsection{Sliver Waste Percentage Result}

As shown by the ANOVA results, all the samples under sliver development (Table 2-waste percentage) shows that the difference in blended ratios has a significant effect on the value of waste percentage. Blended ratios are proven to affect significantly on the waste percentage of the sliver $(p<0.05)$. A probability plot demonstrated higher $\mathrm{R}^{2}$ value of $93 \%$, which indicates stable data distributions. Therefore, data obtained from the experiment can be accepted as stable. Main effects plot of mean data is displayed in Fig. 2 (c). Sliver with $70 \%$ of kenaf was found to exhibit higher waste percentage. Results of $50 \%$ kenaf showed there is less waste percentage produced during the carding process compared to $60 \%$ of kenaf. Based on the results, the increment of kenaf ratios in carding process can affected the percent of waste as kenaf itself cannot become a wrapper fibre and entangled to each other [15]. The waste percentage observed to rise gradually as the kenaf percentage increased. Kenaf fibres, due to their non-uniform fineness and length, do not bind-in properly in the sliver body and become a source of hairiness; therefore, addition of fibres in the blend reduces the effect on sliver quality [16]. 
Table 1: ANOVA test for; a) diameter, b) waste percentage, and c) size (hank)

\begin{tabular}{|l|c|c|c|c|c|}
\hline Source & $\boldsymbol{D} \boldsymbol{f}$ & $\boldsymbol{S S}$ & $\boldsymbol{M S}$ & $\boldsymbol{F}$ & $\boldsymbol{p}$ \\
\hline a) Diameter & & & & & \\
Blended ratios & 2 & 7.230 & 3.615 & 19.80 & $\mathbf{0 . 0 0 2}$ \\
Error & 6 & 1.095 & 0.183 & & \\
Total & 8 & 8.325 & & & \\
\hline b)Waste per- & & & & & \\
centage & 2 & 3.198 & 1.599 & 20.51 & $\mathbf{0 . 0 0 2}$ \\
Blended ratios & 6 & 0.468 & 0.078 & & \\
Error & 8 & 3.666 & & & \\
Total & & & & & \\
& & & & & \\
c) Size sliver \\
(hank) & 2 & 142.03 & 71.015 & 412.58 & $\mathbf{0 . 0 0 0}$ \\
Blended ratios & 6 & 1.033 & 0.172 & & \\
Error & 8 & 143.06 & & & \\
Total & & & & & \\
\hline
\end{tabular}
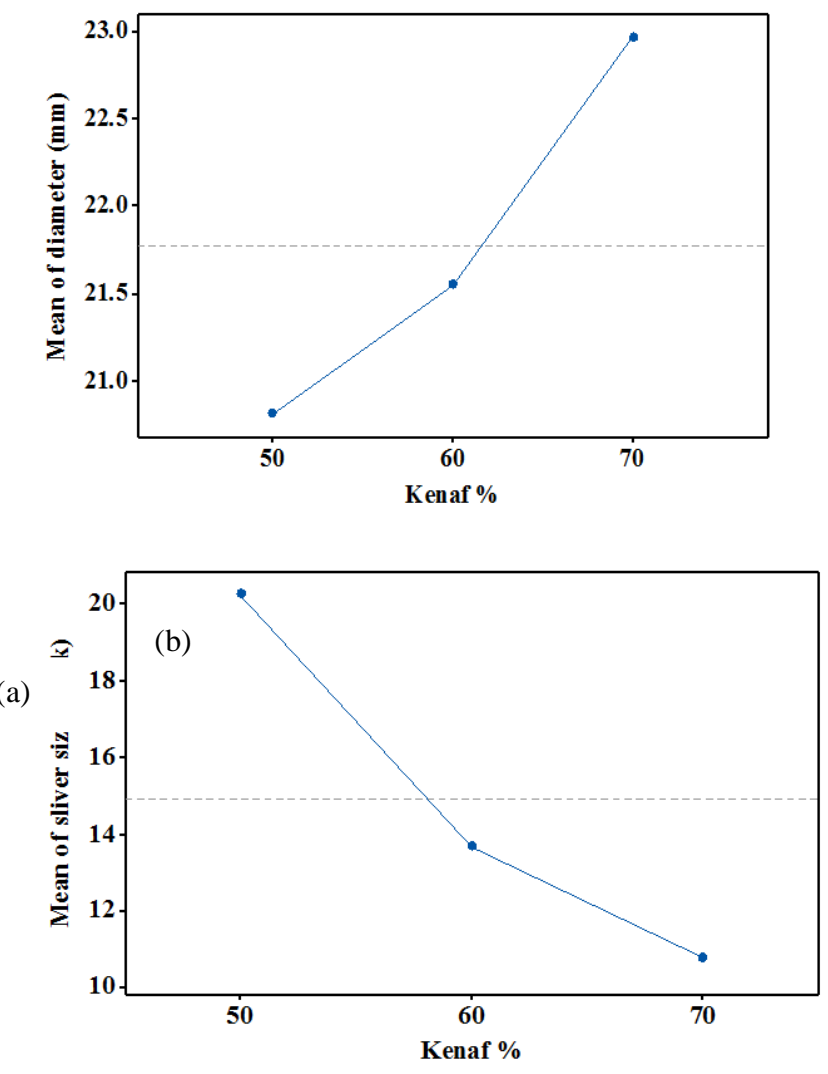

(c)

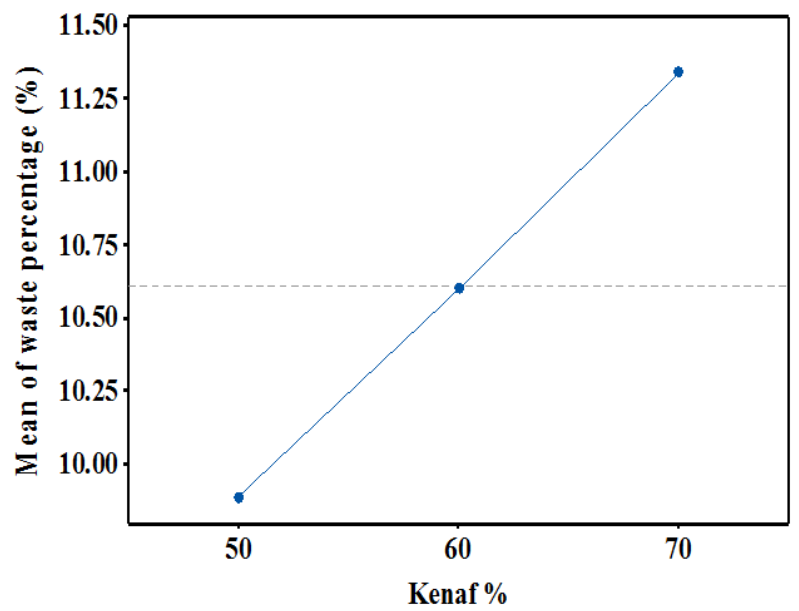

Fig. 2: Main effects plot for; (a) diameter, (b) sliver size, and (c) waste percentage

\subsection{Microscopic View}

Fig. 3 shows the structure of kenaf/polyester blended sliver using digital SLR camera. Whereas, Fig. 4 shows the resulted image under video analyzer with $0.63 x$ magnifications. It can be seen that in general, the kenaf and polyester fiber were blended well. Polyester fibres were found dominant in the sliver and act as wrapper fibres. Kenaf fibers in contrast were only seen lying within the sliver surface.

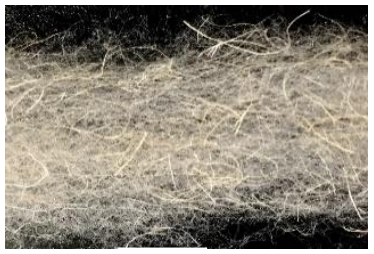

(a)

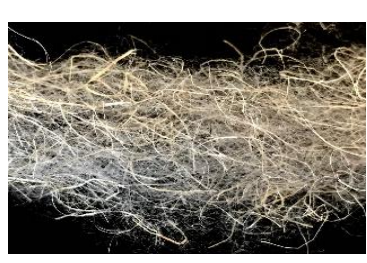

(c)

Fig. 3: Digital SLR camera image of Kenaf/polyester blended sliver with different ratios; (a) 50:50, (b) 60:40, and (c) 70:30

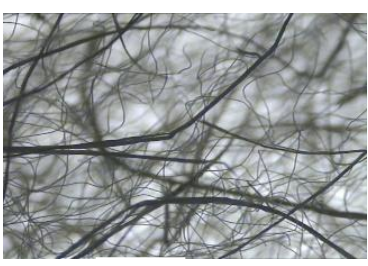

(a)

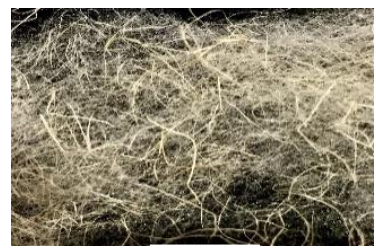

(b)

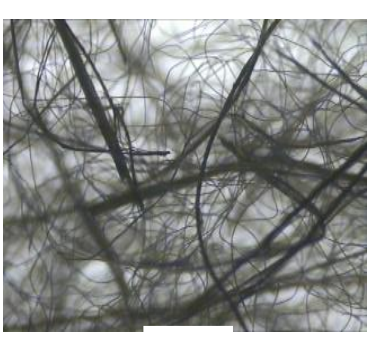

(c)

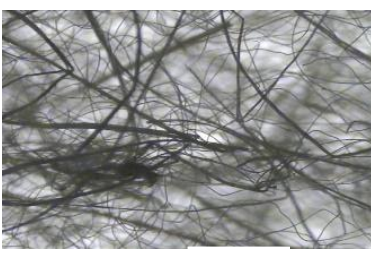

(b)
Fig. 4: Video analyser image of Kenaf/polyester blended sliver with different ratios; (a) 50:50, (b) 60:40, and (c) 70:30

\section{Conclusion}

In this study, effects of the blended ratios on diameter, waste percentage and size (hank) were examined. The influence of blended ratios on the sliver physical properties were found statistically significant $(p<0.05)$. When the kenaf ratios was increased, diameter and waste percentage was also increased, however sliver size values were decreased. The relation between waste percentage and size were inversely proportional. When the waste percentage increased, the size of sliver was decreased.

Sliver quality improved with decreased of kenaf fibres in the blend. This improvement is more prominent when kenaf proportion decreased to $50 \%$ from $70 \%$ as compared to its decreament from $70 \%$ to $60 \%$. The kenaf fibres also did not seen to become wrapper fibres but rather lie within the sliver. Overall, sliver with $50 \%$ ratios gave better results in terms of waste percentage, diameter and size for development of the carded sliver. 


\section{Acknowledgements}

The authors express their immense gratefulness to Kenaf Bio Solution Sdn. Bhd., as a sponsor of kenaf fibre. Special thanks also goes to the Textile Laboratory, Advanced Technology Centre (ATC), Universiti Tun Hussien Onn Malaysia and Textile Laboratory, Universiti Teknologi MARA for providing the facilities for this research.

\section{References}

[1] Azrin Hani AR, Chan TZ, Roslan A, \& Mariati J, "Impact and Flexural Properties of Imbalance Plain Woven Coir and Kenaf Composite", Applied Mechanics and Materials, Vols. 271-272, (2013), pp: 81-85, available online: doi:1-.428/www.scientific.net/AMM.271-272.81, last visit 08.08.2018

[2] Ahmad MR \& Yahya MF, "Tensile Strength and Evenness of Kenaf/Polyetser Blended Rotor-Spun Yarn", Proceeding of the International Colloqium in Textile Engineering, Fashion, Apparel and Design 2014 (ICTEFAD 2014), Springer, (2014), pp: 37-41

[3] El-Shekeil YA, "Influence of Chemical Treatment on the Tensile Properties of Kenaf Fibre Reinforced Thermoplastic Polyethelene Composite", Express Polymer Letters, Vol. 6, No. 12, (2012), pp: 1032-1040, available online: file:///C:/Users/user/Dowloads/EPL0003805_article.pdf, last visit: 13.07.2018

[4] Yuhazri M, Sihombing H, Jeeferie AR, \& Rassiah K, "Mechanical Properties of Kenaf/Polyester Composites", International Journal of Engineering and Technology, Vol. 11, No. 1, (2011), pp: 127 131, available online: https://www.researchgate.net/publication/, last visit: 15.05 .2018

[5] Jeyanthi S, \& Rani JJ, "Improving Mechanical Properties by Kenaf Natural Long Fibre Reinforced Composite for Automotive Structure", International Journal of Physical Sciences, Vol. 7, No. 43, (2012), pp: 5765-5771, available online at http://www.academicjournal.org/IJPS, last visit: 10.08.2018

[6] Ahmad Amel B, Tahir Paridah M, Sudin R, Anwar UMK \& Hussein Ahamed S, "Effect of Fibre Extraction Methods on Some Properties of Kenaf Bast Fibre", Elsevier Industrial Crops and Products, Vol. 46, (2013), pp: 117-123, available online: www.elsevier.com/locate/indcrop, last visit: 27.04 .2018

[7] Muhammad Muslimin H, Mohammad Sukri M, Md Saidin W, Ahmad Mubarak TA, Mohd Idrus MM, \& Farhana Hazwanee J, "Flexural Properties Untreated and Treated Kenaf Fibre Reinforced Polypropylene Composites", AIP Conference Proceeding 1846, http://dx.doi.org/10.1063/1.4983589

[8] Kunal Singha, "A Short Review on Basalt Fibre", International Journal of Textile Science, Vol. 1, No. 4, (2012), pp: 19-28, available online: http://dx.doi.org/10.5923/j.textile.20120104.02, last visit 15.07 .2018

[9] Hasani H, Tabatabaei SA, \& Amiri G, "Grey Rational Analysis to Determine the Optimum Process Parameters for Open-End Spinning Yarns", Journal of Engineering Fibres and Fabrics 81, Vol. 7, No. 2, pp: 81-86, available online: http://www.jeffjournal.org, last visit 06.06 .2018

[10] Raman Bharath VR, Vijaya Ramnath B, \& Manoharan N, "Kenaf Fiber Reinforced Composites: A Review", APRN Journal of Engineering and Applied Sciences, Vol. 10, No. 13, (2015), pp: 54835485, available online www.arpnjournals.com, last visit 17.07.2018

[11] Malik SA, Tanwari A, Syed U, Qureshi RF, \& Mengal N, "Blended Yarn Analysis: Part 1- Influence of Blend Ratio and Break Draft on Mass Variation, Hairiness, and Physical Properties of 15 Tex PES/CO Blended Ring-Spun Yarn”, Journal of Natural Fibres, Vol. 9, (2012), pp: 197-206, available online: http://dx.doi.10.1080/15440478.2012.706446, last visit 15.07.2018

[12] Celik HI \& Kaynak HK, "Effect of Fibre Blending Ratios of Cotton/Polyester Yarns on Retained Splice Diameter", $17^{\text {th }}$ World Textile Conference AUTEX, (2017), pp: 254, http://dx.doi. 10.188/1757-899x/254/14/142005

[13] Ali K, Saeed Shaikhzadeh N, \& Agnes P, "Study on Effect of Blend Ratio on Thermal Comfort Properties of Cotton/NylonBlended Fabrics with High-Performance Kermel Fibre", The Journal of The Textile Institute, (2014), available online: http://dx.doi.org/10.1080/00405000.2014.934045, last visit: 15.05 .2018

[14] Temel E, \& Celik P, "A Research on Spinability of 100\% Polyester and Polyester-Cotton Blend Sirospun Yarns", Textile and Apparel
Research \& Application Journal, Vol. 20, No. 1, (2016), pp: 23-29, available online: https://www.researchgate.net/publication/289715058, last visit: 16.05.2018

[15] Ghosh A, \& Raihan M, "Effect of Fibre Blend Ratios on Yarn Properties", International Journal of Scientific Engineering and Technology, Vol. 4, No. 4, (2015), pp: 243-246, last visit: 16.05.2018

[16] Prakash C, Ramakrishnan G, \& Koushik CV, "Effect of Blend Proportion on Moisture Management Characteristics of Bamboo/Cotton Knitted Fabrics", The Journal of The Textile Institute, Vol. 104, No. 12, (2013), pp: 1320-1326, available online: http://dx.doi.org/10.1080/00405000.2013.800378, last visit 20.07.2018 